\title{
Successful Endosonography-Guided Drainage of an Intra-Abdominal Abscess in a 1-Year-Old Infant
}

Yukiko Ito*, Hiroyuki Isayama*, ${ }^{\dagger}$, Yousuke Nakai ${ }^{*}{ }^{\dagger}$, Gyoutane Umefune*, Tatsuya Sato*, Saori Nakahara ${ }^{\ddagger}$, Junko Suwa $^{\S}$, Keiichi Kato ${ }^{\S}$, and Ryo Nakata*

"Department of Gastroenterology, Red Cross Medical Center, ${ }^{\dagger}$ Department of Gastroenterology, Graduate School of Medicine, The University of Tokyo, Departments of ${ }^{\ddagger}$ Pediatric Surgery and ${ }^{s}$ Anesthesiology, Red Cross Medical Center, Tokyo, Japan

Endoscopic ultrasound (EUS)-guided intervention has been established as a safe, effective and minimally invasive procedure for various diseases in adults, but there have been limited reports in pediatric patients. Herein, we report our experience with successful EUS-guided drainage of an intraabdominal abscess in a 1-year-old infant concomitant with disseminated intravascular coagulation. The abscess was punctured via the stomach using a standard, convex-type echoendoscope, and the patient's condition improved after naso-cystic catheter placement. Although the clinical course was complicated by delayed hemorrhage from the puncture site, the bleeding was successfully managed by endoscopic hemostasis using a standard forward-viewing endoscope.

(Gut Liver 2016;10:483-485)

Key Words: Endosconography; Interventional endosconography; Infant; Abdominal abscess

\section{INTRODUCTION}

Since endoscopic ultrasound (EUS)-guided intervention was developed, its indications have been expanding rapidly. EUSguided interventions have been mainly reported in adults, and data on safety and efficacy in pediatric patients are limited. We experienced EUS-guided drainage of intra-abdominal abscess in a 1-year-old infant with a history of Kasai operation for congenial biliary atresia, complicated by bile leak.

\section{CASE REPORT}

A 1-year-old female infant was admitted to the intensive care unit due to bile peritonitis with 3 days of fever and abdominal pain. She had a history of Kasai operation at the neonatal period for congenital biliary atresia. Computed tomography (CT) scan on admission revealed a massive ascites and paracentesis revealed bile peritonitis, and the patient underwent emergent surgical closure of bile leak at bilio-jejunal anastomosis. However, infection and disseminated intravascular coagulation (DIC) were not improved after surgery. Subsequent CT scan on postoperative day 8 revealed residual fluid collection in the omental sac at the dorsal aspect of the stomach (Fig. 1).

The patient was referred to our department and emergent endosonography (EUS)-guided abscess drainage was performed after full informed consent. EUS-guided transgastric approach

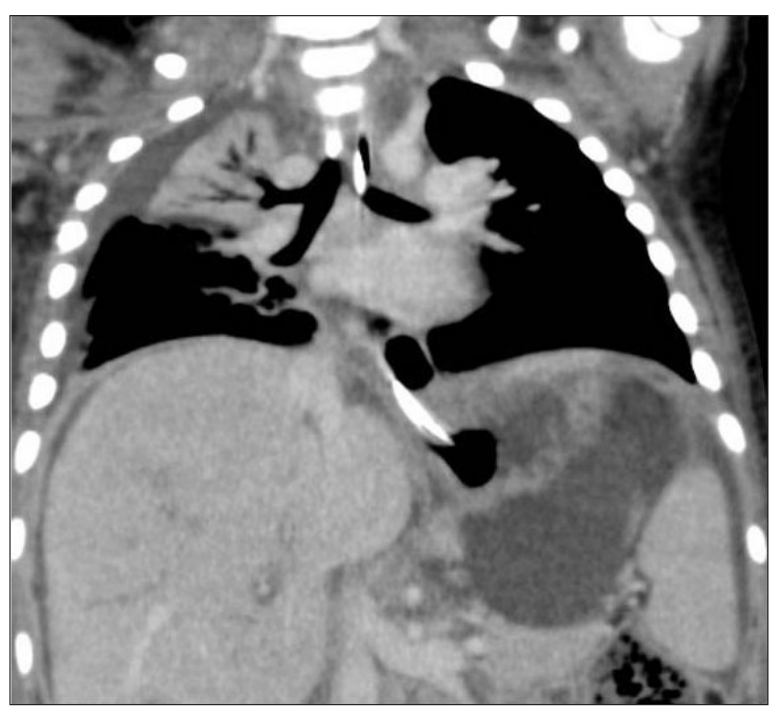

Fig. 1. Computed tomography findings before drainage. Fluid collection in the omental sac is shown from the dorsal aspect of the stomach.

Correspondence to: Hiroyuki Isayama

Department of Gastroenterology, Graduate School of Medicine, The University of Tokyo, 7-3-1 Hongo, Bunkyo-ku, Tokyo 113-8655, Japan

Tel: +81-3-3815-5411, Fax: +81-3-3814-0021, E-mail: isayama-tky@umin.ac.jp

Received on July 16, 2015. Revised on November 9, 2015. Accepted on November 18, 2015.

pISSN 1976-2283 eISSN 2005-1212 http://dx.doi.org/10.5009/gnl15381

@ This is an Open Access article distributed under the terms of the Creative Commons Attribution Non-Commercial License (http://creativecommons.org/licenses/by-nc/4.0) which permits unrestricted non-commercial use, distribution, and reproduction in any medium, provided the original work is properly cited. 


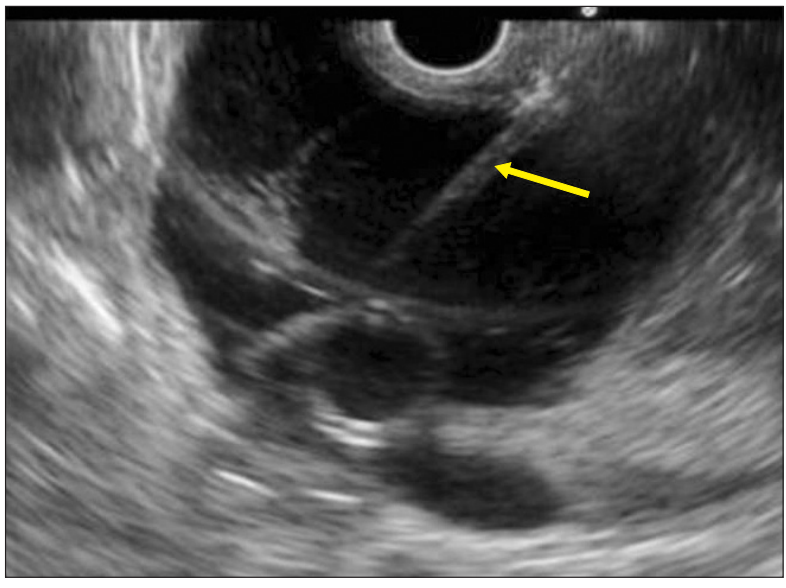

Fig. 2. Endoscopic ultrasound findings and puncture with a fine needle.

was considered safer than percutaneous route which was difficult to avoid hurting the stomach by ultrasonographic observation The patient was $80.1 \mathrm{~cm}$ in height and weighed $9.66 \mathrm{~kg}$. Sedation for the procedure was provided by an anesthesiologist; dexmedetomidine hydrochloride (DEX) $2.0 \mathrm{~mL} / \mathrm{hr}(0.8 \mathrm{mg} /$ $\mathrm{kg} / \mathrm{hr}$ ), fentanyl $20 \mathrm{mg}$ and three times of midazolam $1 \mathrm{mg}$. A muscle relaxant, rocuronium bromide $10 \mathrm{mg}$, was injected intravenously just before inserting the echo-endoscope. The patient was intubated and placed in the left lateral decubitus position, and bent backwards, with her mandible and forehead firmly grasped to allow scope insertion. The echo-endoscope (UCT260; Olympus Medical Systems Corp., Tokyo, Japan) was then inserted while linearizing the insertion axis. The fluid collection containing debris and fibrin was visualized on EUS from the stomach. EUS-guided puncture of abdominal abscess using a flexible 19-gauge fine needle aspiration (FNA) needle (Expect slimline 19 gauge Flex; Boston Scientific Corp., Natick, MA, USA) was performed (Fig. 2) and brownish cloudy fluid was aspirated. A 0.025-inch guidewire (VisiGlide 2; Olympus Medical Systems Corp.) was inserted deep into the abscess cavity, followed by tract dilation by a 6-F coaxial cautery dilator (CystoGastro set; ENDO-FLEX GmbH, Germany). Finally, a 7-F pigtail naso-cystic drainage tube was successfully inserted. During the procedure, no difficulty was encountered in the manipulation of the echoendoscope.

Infection and DIC resolved after EUS-guided abscess drainage and CT scan 2 days after the procedure revealed resolution of abdominal abscess. However, one the next day, hematemesis was observed without bleeding from the nasocystic tube, and emergent upper endoscopy was performed using a standard endoscope (GIF Q260J; Olympus Medical Systems Corp.). Active bleeding was seen at the puncture site of EUS-guided abscess drainage in the stomach, and hemostasis was obtained by clipping after removal of nasocystic tube. She was discharged 14 days after EUS-guided drainage without any recurrence of bleeding or abdominal abscess.

\section{DISCUSSION}

EUS and EUS-FNA in pediatric patients have been increasingly utilized, but EUS-guided intervention, i.e., EUS-guided drainage of pseudocyst is rarely reported. ${ }^{1,2}$ For the drainage of intraabdominal abscesses in children, laparotomy or percutaneous drainage is commonly used, with a reported improvement rate of from $50 \%$ to $80 \% .^{3-5}$ When percutaneous drainage is difficult due to the location, endoscopic drainage can be a less invasive alternative to laparotomy. There are two issues in pediatric EUS: sedation and lack of dedicated devices. In this case, we were able to insert a regular echoendoscope safely even in a 1-yearold infant, by providing sedation with intravenous anesthesia using a small amount of muscle relaxant, and bending the patient's mandible backwards to linearize the insertion axis of the echoendoscope. General anesthesia is commonly employed for pediatric endoscopy, but intravenous anesthesia can be an option. For intravenous anesthesia, propofol, fentanyl and/or midazolam are often used. ${ }^{6,7}$ We were able to provide safe and effective sedation by using DEX, fentanyl, and midazolam. In addition, additional muscle relaxation with rocuronium bromide enabled the safe insertion of an echoendoscope and consequently allowed completion of the whole procedure.

Under EUS guidance, puncture of the blood vessels can be avoided, but the burning effects of a cautery dilator can cause delayed bleeding by inflammation extending to the surrounding mucosa. Self-expandable metallic stent (SEMS) was reported as effective in prevention and treatment of both leakage and bleeding from puncture site. ${ }^{8,9}$ Although bleeding was easily controlled by endoscopic application of clips in this case, SEMS can be inserted through the fistula if bleeding is difficult to control. The use of a cautery dilator, though effective, might not be needed in this case because the inserted drainage tube is thin.

In conclusion, we experienced successful EUS-guided drainage for intra-abdominal abscess in a 1-year-old infant using a standard echo-endoscope. With the assistance of anesthesiologist and the appropriate posture, the procedure could be completed without difficulties. EUS-guided interventions should be considered as a treatment option in pediatric patients.

\section{CONFLICTS OF INTEREST}

No potential conflict of interest relevant to this article was reported.

\section{REFERENCES}

1. Artifon EL, Ferreira F, Baracat R, et al. EUS-guided fistulization of postoperative colorectal stenosis in an infant with Hirschsprung's disease: a new technique. Gastrointest Endosc 2012;75:459-461. 
2. Scheers I, Ergun M, Aouattah T, et al. Diagnostic and therapeutic roles of endoscopic ultrasound in pediatric pancreaticobiliary disorders. J Pediatr Gastroenterol Nutr 2015;61:238-247.

3. Duszak RL Jr, Levy JM, Akins EW, et al. Percutaneous catheter drainage of infected intra-abdominal fluid collections. American College of Radiology. ACR Appropriateness Criteria. Radiology 2000;215 Suppl:1067-1075.

4. Gervais DA, Ho CH, O'Neill MJ, Arellano RS, Hahn PF, Mueller PR. Recurrent abdominal and pelvic abscesses: incidence, results of repeated percutaneous drainage, and underlying causes in 956 drainages. AJR Am J Roentgenol 2004;182:463-466.

5. vanSonnenberg E, Wittich GR, Goodacre BW, Casola G, D'Agostino HB. Percutaneous abscess drainage: update. World J Surg 2001; 25:362-369.

6. Attila T, Adler DG, Hilden K, Faigel DO. EUS in pediatric patients.
Gastrointest Endosc 2009;70:892-898.

7. Amornyotin S, Aanpreung P, Prakarnrattana U, Chalayonnavin W, Chatchawankitkul S, Srikureja W. Experience of intravenous sedation for pediatric gastrointestinal endoscopy in a large tertiary referral center in a developing country. Paediatr Anaesth 2009;19: 784-791.

8. Iwashita T, Lee JG, Nakai Y, Samarasena JB, Chang KJ. Successful management of arterial bleeding complicating endoscopic ultrasound-guided cystogastrostomy using a covered metallic stent. Endoscopy 2012;44 Suppl 2 UCTN:E370-E371.

9. Iwashita T, Lee JG, Nakai Y, et al. Successful management of perforation during cystogastrostomy with an esophageal fully covered metallic stent placement. Gastrointest Endosc 2012;76:214215. 